\title{
LA IMPORTANCIA DEL CINE DOCUMENTAL EN LA FORMACIÓN DEL ESTUDIANTE
}

\author{
THE IMPORTANCE OF DOCUMENTARY FILM IN STUDENT TRAINING
}

\author{
iD Alexandre Buccini \\ Doutor em Ciencias de La Educación (Concentração em Sociologia do Cinema e Educação). \\ Universidad Nacional de Cuyo - UNCuyo \\ Mendoza - Província de Mendoza - Rep. Argentina \\ alexandrealmodovar@gmail.com
}

Resumo: Aunque el cine de ficción sea mucho más utilizado en las escuelas, el documental trae grandes posibilidades educacionales. El objetivo de este artículo fue apuntar brevemente la importancia de la relación entre cine y educación, y traer informaciones sobre el cine documental. Metodológicamente, fue utilizada la revisión sistemática cualitativa, en busca de artículos publicados entre enero de 2006 hacia diciembre de 2018. O sea, se realizó una búsqueda bibliográfica, siguiendo técnicas de la línea de investigación descriptiva y de relación entre variables para fundamento empírico-teórico. Resaltase que este Trabajo es parte de la tesis doctoral del autor. Es comprobable que el cine documental trae un impulso a la formación crítica de los estudiantes, haciéndoles cambiar sus percepciones de la realidad social.

Palavras-chave: educación libertadora; cinema y educación; creación cinematográfica.

Abstract: Although fiction cinema is much more used in schools, the documentary brings great educational possibilities. The objective of this article was to gently point out the importance of the relationship between cinema and education, and to bring information about documentary cinema. Methodologically, the qualitative systematic review was used, in search of articles published between January 2006 and December 2018. That is, a bibliographic search was carried out, following techniques of the descriptive line of research and the relationship between variables for empirical foundation-theoretical. It should be noted that this work is part of the author's doctoral thesis. It is verifiable that documentary film promotes the critical training of students, making them change their perceptions of social reality.

Keywords: liberating education; cinema and education; cinematographic creation.

\section{Para citar - ABNT NBR 6023:2018}

BUCCINI, Alexandre. La importancia del cine documental en la formación del estudiante. Cadernos de Pósgraduação, São Paulo, v. 20, n. 1, p. 4-15, jan./jun. 2021. Disponível em: https://doi.org/10.5585/cpg.v20n1.19339. 


\section{Introducción}

Vivimos una época de comunicación generalizada, en la que toda la información está mediada por Internet, cine, TV, etc., a través de medios predominantemente visuales, formando un momento crucial en la historia en que la crisis de la modernidad pone en retirada los viejos sentidos de la familia, de la religión y los valores tradicionales. El sociólogo alemán Jürgen Habermas (1984) llama a este período en el que situamos nuestro estudio como la era de los medios de comunicación. En ese contexto, Habermas (1984) trató de dar respuestas a las preguntas sobre el papel de la educación y su importancia, frente al bombardeo de estímulos visuales que los estudiantes reciben y cómo se debería preparar a los jóvenes para hacer frente a los principios éticos de una sociedad en transformación.

En esta era comunicativa, la escuela mantiene el desafío de cambiar la lógica de construcción de conocimientos, porque el aprendizaje ocupa ahora la totalidad de nuestra vida, y porque pasamos gran parte de nuestra vida en la escuela debemos sentirnos felices aprendiendo. En consecuencia, la felicidad en la escuela no es una cuestión de metodología o elección ideológica, es una obligación esencial en sí misma. Como argumenta Georges Snyders (2001, p. 87), necesitamos una nueva cultura de la alegría, "la alegría de la religión, no necesariamente originaria de Dios, pero algo transcendiente, que construye un mundo mejor para las generaciones futuras. El mundo de hoy és 'favorable a la satisfacción'... y la escuela también puede (deve) ser".

Desde ese punto de vista, el cine corresponde claramente a las necesidades del discurso visual de la escuela del presente y del futuro, pues las películas son un conjunto atractivo de imágenes y sonidos. En este sentido, el uso en el aula del cine de ficción ha sido estudiado y muy debatido en América Latina. Pero la razón principal para una búsqueda como la que propone este artículo deriva del hecho de que la película, por sus propiedades, genera la creación de un mundo privado con su propio idioma en el proceso de cognición, creación, ejecución y exposición. Así, en los largometrajes de ficción, como afirma Bill Nichols (2005), el control del universo está representado, desde el principio, por las manos de los responsables del diseño de la película; mientras que, por su parte, en el documental, el control se adquiere gradualmente, e implica reflexionar más profundamente sobre las necesidades y los sentimientos de los participantes.

Nuestra investigación fue más allá de la mera búsqueda al proponer en la escuela foros estéticos que conciernen al placer y disfrute de la belleza, siguiendo a Paulo Freire (2000), quien considera que la promoción de la ingenuidad y la importancia requerida no puede o no debe ejercerse sin considerar también la formación ética rigurosa, siempre unidos a la estética, la percepción 
de la decencia y la belleza, y el modo en que van de la mano en la práctica educativa y el testimonio de sus resultados positivos en la formación de los estudiantes.

Al mismo tiempo, lo que estamos hablando aquí es de la construcción de un discurso basado en la aparición de lo que llamamos real. Esa fue la base del cuestionamento: Si los estudiantes elaboran productos audiovisuales según las características del cine documental, por su razón de ser registro de la realidad (aunque sea un registro realizado desde la subjetividad de cada estudiante), es posible que ellos modifiquen sus modos de relacionarse con esa realidad y realicen acciones ciudadanas?

De hecho, es importante poner en relieve que esta pregunta fue una las cuestiones norteadoras de nuestra tesis doctoral; lo que nos lleva a también añadir que este artículo solamente reserva una pequeña muestra de aquella investigación, la cual comprobó, por medio de custionários y la realización de películas con estudiantes, que sí, hacer documentales exige que los alumnos submerjan en un universo diferente del suyo, y, con eso, pasan a mirar al mundo de un otro modo, más humanizado y más crítico, cambiando sua opiniones e percepciones de la realidad. Aquí, lo que se propone como objetivo es apuntar bevemente la importancia de la relación entre cine y educación, $\mathrm{y}$ traer informaciones sobre el cine documental.

En este estudio se optó, por un lado, por la revisión sistemática cualitativa, que se realizó en bases de datos científicas, en busca de artículos publicados entre enero de 2006 hacia diciembre de 2018. Así que, en primer lugar, se realizó una búsqueda bibliográfica, siguiendo técnicas de la línea de investigación descriptiva y de relación entre variables para dar fundamento empírico-teórico al estudio, caracterizándose la pesquisa cualitativa.

En el área de la educación se cree hoy que investigar las relaciones que los estudiantes establecen con artefactos audiovisuales puede ayudar a comprender la función que desempeñan los medios de información en la rutina diaria de los infantes, en su formación moral y ética y en sus procesos de construcción del conocimiento. Tales estudios también pueden llegar a contribuir con respuestas a algunos de los problemas identificados en las escuelas, como cuestiones relacionadas con las distintas capacidades de percepción y atención, entre otros, lo que justifica social y academicamente este trabajo, intentando contribuir para la evolución de estos estudios.

\section{Cine y Educación}

Como el hombre es un ser social, la lucha por su liberación ocurre en el escenario de la sociedad, aunque sometida a modelos de desigualdad, marginación y miseria - tal como se encuentran en la sociedad latinoamericana en general. Para Freire (2005), los que enseñan son los que oprimen y por eso deben ser concientizados del papel liberador que podrán asumir. Es el profesor 
quien se modela en la concepción de hacer del alumno un mero depositario de conocimiento (el modelo bancario), considerando, de hecho, al estudiante como incapaz de producir conocimiento por sí mismo, desconsiderándolo como un ser en formación continua.

Freire (2005) también lanza la idea de una teoría de la acción dialógica en la que la acción transformadora se hace a través de la reflexión y acción, donde el diálogo de los oprimidos pueda emerger, en la forma de praxis social, en el seno de la sociedad dominante. El carácter revolucionario de los oprimidos, en su acción transformadora, es una acción pedagógica de la que surgen nuevas posibilidades de renovación social. La concientización se da a lo largo de un proceso gradual en el que se busca la libertad sin producir opresores y oprimidos, sobre todo porque opresores y oprimidos son también víctimas de la misma inconsciencia. Se revoca, así, la estructura social a través de la concientización del hombre sobre su papel en la historia, distanciándose de las imposiciones apriorísticas producidas por las minorías dominantes.

La liberación del individuo en una sociedad extremadamente competitiva pasa por el reconocimiento de su lugar, debido a que se constata que la posición del otro no es respetada ni valorada. El desconocimiento del individuo de "ser otro" puede contribuir a que asuma papeles tanto de opresor como de oprimido. La educación dialógica propone, en ese contexto, el respeto por la diversidad, en que cada persona, incluso permeada por diversas relaciones de poder, podría promover innumerables configuraciones de autonomía y libertad por el hecho de que ellas son, antes que colectivas, una condición y una determinación personal e individual. Freire (1996) amplía la comprensión de cómo se da la capacidad de mediación ante las condiciones ambientales y sociales, en las cuales las personas están insertadas y donde promueven y viabilizan tanto opresión como autonomía, lo que conlleva la búsqueda por mejores condiciones de desarollo individual y colectivo.

Por outro lado, según Aumont y Marie (2003), aun siendo el arte de la modernidad, el cine todavía es nuestro contemporáneo. No fue destronado por televisión, internet, vídeo digital, incluyendo amateur, en fotografía en el teléfono, o por videojuego. Como ocio de masa, ciertamente, salas de cine surgieron en los países de América Latina y los países de Europa. Los estrenos y la difusión en DVD han impuesto una pedagogía obligatoria, en la cual es imposible ver una película sin que se imponga su genealogía. Imagínase que con la música se absorbe la entrevista, el ingeniero de sonido, las tomas que no hubieran dado cierto, etc. Aumont y Marie (2003) nos dicen que incluso el cine siendo agarrado con un fenómeno económico de la modernidad, en mayor o menor medida, las dos maneras de pensar, como arte (cine de autor) o producto (hechos para proporcionar entradas disponibles, independientemente de la calidad o valor artístico e innovador), siguen siendo hoy, a veces aisladas y antagónicas, a veces conciliatorias. 
Por otro lado, como subraya Lacan (1998), para contribuir a la formación del sujeto consciente, el reconocimiento del valor de la imagen es un proceso progresivo y de adquisición histórica de la humanidad. Hasta llegar a la explosión multimediática conectadas a la rede, las imágenes se superponen inconexas y al azar, típico de una sociedad futura, fraccionada en múltiples significados que se desvinculen en varios rostros.

La duplicación de imágenes produce una fascinación con la cual el individuo mantiene una relación privada con el mundo a través de la telepresencia: viendo a la distancia (tele) el individuo utiliza un telescopio respecto del mundo, el cual es satisfactorio para el ego. Sin embargo, no es una tele realidad paranoide, aunque el peso del significante agregue la velocidad desmoralizante de la verdad en su intensidad, proponiendo un poder reglamentario, a través de formularios capturados por la mirada, que Lacan atribuye al inconsciente, como bien traduce Sodré (1992). En la estructuración de las relaciones humanas de una manera nueva, la telerrealidad demuestra su poder en la forma social por el predominio del libre mercado, lo que significa que desea integrar, organizar y controlar todos los poderes de la subjetividad. Según Sodré (1992), para incorporar todas las técnicas de reproducción desarrolladas en la modernidad y también los modelos de organización de la vida social en términos de novedad y simultaneidad, la televisión, en sus proyectos de absorción, ofreció espacio y tiempo no reales, o simulados, en el existencialismo del espectador.

En este orden de simulacros industrial, el ojo pide, más que nunca, por la civilización de la escritura, de la fotografía y del cine. Todas las ideas a las que propuso Freire $(1996,2005)$ van al encuentro de lo que sea la educación deseable en nuestra era, con una estructura dialógica, permeable, accesible, pero, sobre todo, transformadora. En estos dos puntos se encuentra la importancia de se enganchar el cine a la educación: de un lado, lo inevitable que es intentar huir de la realidad de la avalancha audiovisual de nuestra época y como influye en la construcción del pensamiento; y, por outro lado, la necesidad de creación (o fortalecimiento) de una estructura dialógica, transformadora y estimulante en los procesos educacionales.

\section{El cine documental}

El clásico documental producido en los años 1950 hizo afirmaciones sobre el mundo a través de la narración, en general realizadas de manera autoritaria. Ya en el caso de documentales directos, las pretensiones de la verdad se hacen a través de los diálogos (testimonios, entrevistas), con una participación más activa del cineasta. En el documental la voz directa pierde su autoridad, es sólo una voz más. El documental narrativo se caracteriza, entonces, por la intención social, presencia de voiceover, presencia de entrevistas y testimonios, el uso de imágenes de archivo, poco uso de actores profesionales, en particular el tamaño y de la intensidad, procedimientos para la 
toma de la cámara de mano, imágenes temblorosas, la improvisación, el uso de guías abiertas y el énfasis en la indeterminación de las tomas, la explotación de imágenes y del sonido. En ese contexto es importante resaltar lo que nos apuntó Paranaguá (2003, p. 53):

\footnotetext{
Cine mudo y cine sonoro tienen entre sí tantas diferencias que no resulta exagerado hablar de una verdadera revolución, tecnológica y estética. Pues bien, para el documental la gran ruptura, la auténtica revolución ocurre con la llegada del sonido directo. Hasta entonces, el documental podría describir al otro, pero no brindaba acceso a su palabra.
}

No es fácil determinar las diferencias y los límites entre el género documental y las intenciones del periodismo documental, generalmente expresada por el género reportaje. En principio, el documental es un género más elaborado, más largo y con pretensiones de la realidad, de verdad en sus detalles más sublimes. Para Paranaguá (2003, p. 25), "una verdadera historia del documental sólo será posible cuando logre integrar en su ámbito el mainstream de la producción institucional, los noticieros". El periodismo documental, aunque también persiga los hechos y la verdad que se deriva de ellos, es un género más adaptable a la televisión, por ejemplo, porque es una fórmula más barata y más aceptable. En ese sentido, "la mayoría de los noticieros tienen una difusión estrictamente nacional o local. Sobreviven gracias al apoyo y al sometimiento a los intereses del Estado" (PARANAGUÁ, 2003, p. 35), y, así, “ciertos documentales adquieren con el paso del tiempo un alcance insospechado en su momento (PARANAGUÁ, 2003, p. 25). Eso porque, muchas veces, “el peso de los patrocinios políticos, comerciales, financieros, ideológicos sobre los noticieros tampoco está ausente del documental producido en una configuración distinta (PARANAGUÁ, 2003, p. 23).

Definiendo los balizamientos para entender el cine documental como género investigador de hechos, es necesario tener en mente algunas de sus característica:

Divulgación prácticamente limitada a los canales de TV educativa o de los canales de TV a cable y algunas salas de cine. La película documental requiere, además del mayor tiempo de preparación, una exclusiva participación de profesionales que trabajan en su aplicación en relación con el periodismo.

Su carácter copyright. Documental es un género fuertemente marcado por la mirada del director en su objeto, revelando la sensibilidad del cineasta. El cineasta de documental João Moreira Salles afirma que el director del documental no es nada si no tiene los derechos de copyright, si no es el propietario, y esto no cae sobre la credibilidad del documental, mientras que el periodismo se carga un aura de objetividad, casi anónima. También se considera que el documentalista tiene mayor probabilidad de uso de recursos en la construcción de los textos de ficción, sin correr el riesgo de ser acusado de manipular información, dañando su credibilidad. El documental es copyright y es 
subjetivo, mientras que la demanda de periodismo documental mascarilla esta subjetividad. El documental busca la moraleja de la historia, mientras que el periodismo documental presenta los hechos, el reportero-narrador no compromete la búsqueda. Además, mientras que en periodismo documental siempre es necesaria la presencia de un narrador, en documentales, testimonios hablan por sí mismos.

En el campo del lenguaje, en el periodismo hay la obligación de la presencia de un narrador. ¿Qué define una diferencia explícita en relación con el documental y el periodismo? Que el último necesita un narrador o periodista a revelar los reportajes o noticias, y el documental puede ser construido a través de los testimonios y la paráfrasis cognitiva, que aporta nueva información, asî como el juego de imágenes y el montaje que se comunican con el espectador, sin imponer una 'vOz de Dios', que dicta los caminos de entendimiento.

Uso de imágenes y testimonios, funcionando como documentos. Hay recorte de la realidad y trabajando como registros. El documental busca mapear hechos correlacionados, sucesos concatenados, causas y consecuencias. Hay documentos históricos y científicos, materiales e inmateriales, que funcionan en la forma de reporte de caso.

- Amplio uso de montajes ficticio para simular hechos. Son usados personajes, metáforas y elementos ficticios, figuras, gráficos e índices para convencer al público de que la información tiene credibilidad. Hay reconstrucciones del pasado, que pueden inspirar, principalmente en documentales históricos y científicos, siempre que el ritual tenga la credibilidad de los testigos o documentos.

Breschand (2004, p. 17), por su parte, apunta que "los cineastas harán del documental el lugar de una toma de conciencia del mundo, de sus múltiples niveles de realidad, de una forma que ni las actualidades, demasiado elípticas, ni la ficción, demasiado artificial, los presentan a los espectadores". Todo lo que se ha desarrollado con las transformaciones sociales de la primera mitad del siglo XX, como la crisis de 1929, las guerras, etc., hicieron que el documental fuera posicionado como un dispositivo, como una herramienta, también utilizada por el mismo gobierno para unificación de la población, y la construcción del sentimiento de nacionalidad. Además de eso, afirma Breschand (2004, p. 43): "una de las facultades del documental es la de unir estaciones, confrontar épocas, medir el tiempo que transcurre y ver qué es lo que se trasnforma".

Aunque cada documentalista presenta diferentes posiciones con respecto a las configuraciones relacionadas con el género, es posible comprobar algo en común entre las expresiones utilizadas por ellos, si el periodismo o el cine. Téngase en cuenta que todos consideran el carácter autoral de sus producciones y retratan el día a día del espectador para despertar la reflexión en torno a la realidad en la que viven. Sin embargo, se trata de un consenso entre los investigadores afirmar el aspecto personal del documental, que actúa en cierta realidad a ser retratada, ya sea en 
vídeo o en película. En este contexto, la actuación del periodista en producciones documentales adquiere el carácter autoral que se opone a la definición de periodismo imparcial y libre, criticada por muchos profesionales en el área.

De acuerdo con Manuela Penafria (2001), el documental tiene el objetivo de atraer la atención de los espectadores para la crónica diaria, estableciendo una conexión entre los eventos. Subraya que la principal función del género es "estimular o diálogo sobre diferentes experiências, com maior ou menor intensidade sentida". En toda la trayectoria histórica del cine documental, desde el comienzo del siglo pasado, los temas abordados en el cine o en la televisión siempre implican la realidad de ciertos hechos o personas. Con ello, se refuerza la teoría de que puede ser un instrumento importante para el conocimiento real de los acontecimientos, para comprender los mecanismos de la construcción de esa realidad.

Sin embargo, hay un gran debate, alentado por autores que defienden la teoría de que este género tiene distintas características del periodismo, su definición implica posiciones divergentes. El género tiene como una de sus principales características, su carácter de autoría y no puede ser definido como algo periodístico, puesto que esto debe ser justo e imparcial. Otros sienten que el periodismo ideal puede también ser autoral, porque el reportero se ve y se siente sobre el hecho de las exposiciones, haciendo que la imparcialidad sea un mito. Sobre la base del debate mencionado, está comprobado que no es posible establecer parámetros fijos sobre el documental, sea utilizado por periodistas o cineastas. La investigadora Cristina de Melo (2002), en su trabajo presentado en el Núcleo de Investigación en los medios audiovisuales, en el $25^{\circ}$ Congreso Anual en Ciencias de la Comunicación, realizado en Salvador, Bahia, Brasil, dice que "el facto de ser un discurso sobre el real y utilizar imágenes en loco son características que distinguen el documental de la práctica periodística” (MELO, 2002, p. 5).

La producción de documentales realizados por los periodistas indica preocupación en el uso de uno de los interrogatorios poco empleados de conducir: por qué. Sin embargo, la práctica profesional diaria de periodismo, si regresamos a la transmisión de los hechos visibles, es puramente cuantitativa y fáctica, sin impugnar las razones que han llevado a la realidad.

Contrariamente a lo que se transmitió en el sistema comercial, la TV pública viene a satisfacer los objetivos del video documental, en la movilización y el carácter participativo de la comunidad. En ella, así como en el video documental, existe la explotación de narrativas en que traducen las culturas populares locales comunes. La importancia del video documental, mientras movilizador de la sociedad, se desarrolla a partir de la contextualización de los hechos, se pone de manifiesto al valorar el aspecto personal, en el que los individuos se ven reforzados y depositan sus ideales y sueños a la espera de sus propios logros. En este sentido, Cilicia Peruzzo (1998) afirma que el 
hombre tiene como esencia, el potencial para ser sujeto de la historia. En estas condiciones, se deforma, si embrutece, es deshumanizante. Por último, el uso de video documental debe suscitar la participación popular y contribuir a la formación de la ciudadanía, fomentando, a su vez, la práctica profesional en una nueva práctica de comunicación.

Paradójicamente, fue el documental que introdujo en el periodismo el lenguaje cinematográfico y diversas innovaciones formales. La necesidad de conectar las fibras discontinuas de escenas del día, sin ninguna programación previa, ha obligado a los directores a audacias formales en los montajes, abandonando las estructuras tradicionales de la narración, que fueron sustituidas por una visión más impresionista y fragmentaria. Así, esta heterodoxia narrativa, añadida a la movilidad y más o menos hábil manipulación de la cámara, constituyen una fuente de constante renovación para el cine.

Los documentales se han multiplicado debido a la demanda de las cadenas de televisión y la necesidad de que el público pueda interpretar el propio hoy a través de las crónicas históricas. El desarrollo de los montajes permite el cultivo de nuevos planes estéticos, estimula también por la creciente tendencia a la producción de películas fuera de los estudios, en el que se refuerza la posibilidad de capturar escenarios naturales y urbanos. Así, documentales, además de experimentar el paralelismo y la sincronización con las películas de ficción, asimilaron las nuevas perspectivas de la investigación y la apertura a otros engranajes, aprovechando las nuevas posibilidades. Como apunta Breschand (2004, p. 80), “a una sucesión de testimonios, aparentemente opuestos pero en realidad complementarios, responderán intermitentes inmersiones en el pasado lejano o próximo que suscitan ecos en ocasiones discordantes". O sea, que el documental siempre será contrapuntístico.

En ese contexto, hay quienes consideran el cine como un arte del sueño, como señala el gran cineasta surrealista Luis Buñuel:

\begin{abstract}
O mecanismo que cria a imagem cinematográfica é, por seu próprio funcionamento, a forma de expressão humana que mais se assemelha ao trabalho da mente durante o sono. Um filme parece ser uma imitação involuntária do sonho... A escuridão que gradualmente invade a sala é o equivalente ao fechar dos olhos. É o momento em que a incursão noturna ao inconsciente começa na tela e nas profundezas do ser humano. Como no sonho, as imagens aparecem e desaparecem em dissoluções, e o tempo e o espaço se tornam flexíveis, contraindo-se ou se expandindo à vontade. A ordem cronológica e a duração relativa não correspondem mais à realidade (BUÑEL, apud CARRIERE, 2006, p. 84).
\end{abstract}

Cualquiera sea la definición, no hay duda de que el cine permanece como una de las más sólidas manifestaciones del arte y la expresión humana. Incluso con el protagonismo de la televisión, desde los años 50, la producción cinematográfica no se interrumpió, ya que los productores de cine también trabajan para la televisión, sin abandonar la profesión de origen y su nivel de excelencia. Además, el cine - y su especialización documental - ha ganado diversos sectores los como 
laboratorios, como instrumentos de investigación; la enseñanza en escuelas y universidades; apoyo publicitario en el comercio y la industria; entretenimiento y medios de expresión individual.

El gran éxito del cine y su influencia social han apoyado la profunda ilusión de la realidad que rodea a los acontecimientos en la pantalla. Es un hecho que esta ilusión está hoy siendo contrarrestadas por un análisis del cine como medio de comunicación y estética. La supuesta objetividad completa asignada al cine es un viejo mito que apoya en carácter óptico-mecánicos de registro de imágenes fotográficas. La fascinación que produce el efecto verdad de la película está en el origen de las diversas teorías, tales como el Cine-ojo y Cine-verdad. El cine verdad o directo influyó notablemente en las técnicas modernas de producción de documentales de la televisión documental y el periodismo. Las imágenes proyectadas en la pantalla no escapan de ciertos principios oficiales de redacción, incluso aquellos sujetos a cierto rigor documental, en las películas hechas por la simple adición de planes, es decir, películas que consta únicamente de las secuencias filmadas en su tiempo real y un espacio continuo. Se sabe que la película no puede escapar a la interpretación de sus directores, a los trabajos de montaje, manipulación de planes y cambios inherentes en el set de filmación.

\section{Consideraciones finales}

La escuela del siglo XXI debe tener nuevos proyectos y conjuntos de datos para hacer sus propias innovaciones, mediante la planificación a mediano y largo plazo, haciendo su propia reestructuración curricular para ser, finalmente, un centro de formación de ciudadanos. Los cambios deben venir desde dentro de las escuelas para ser más duraderos, y de la capacidad de innovar, grabar, organizar sus prácticas y experiencias dependerá su futuro. En este sentido, el profesor debe ser un facilitador del conocimiento, y el estudiante, el sujeto de su propia formación, construyendo el conocimiento de lo que él mismo hace. Por esta razón, tiene que ser curioso y esforzarse por identificar nuevas rutas de generación del conocimiento. El educador debe, en la visión freireana, prepararse para entrar en la transformación del contexto social, lo que se obtendrá a través de la nueva pedagogía emancipadora. Enseñar a pensar y problematizar sobre su realidad sería, entonces, la forma correcta de reproducir conocimiento, pues es, a partir de ahí, que el educando tendría la capacidad de comprenderse como un ser social. Una vez conocida su situación en la sociedad, el educando jamás aceptará la condición de oprimido, sino que buscará la igualdad.

Por outro lado, el cine se ha convertido, con el tiempo, en un arte popular, oponiéndose a las artes de elite, decantada durante más de mil años de historia. En sus comienzos, el arte cinematográfico ha sido rechazado por los bien nacidos, como si fuera la manifestación de villanía, y hoy 
en día la situación ha cambiado completamente, porque la sensación que tenemos es que, indiscriminadamente, cualquiera va al cine sin perjuicio o culpabilidad.

Aún así, actualmente el cine es negocio e implica una perspectiva industrial, reuniendo a especialistas en diversas áreas. La autoría de las películas expone un pequeño mundo de artistas, artesanos, técnicos de distintos orígenes que, durante un período de tiempo específico y limitado, vivirán una experiencia socializada. Las artes que fueron practicadas por una sola persona expresaron su individualismo y tuvieron relativamente poca participación. Al contrario, los directores de cine reflejan sus propias convicciones y alternativas en el trabajo de la confección de películas, pero, en realidad, representan también una autoría y firma, demostrando que este pequeño mundo puede reflejar una realidad que seduce y fascina al público. El director quiere imprimir su marca, quiere la libertad para disparar, divulgar su narrativa personal. En ese sentido, por su parte, debe recibir las garantías económicas de la producción industrial, que con frecuencia influyen en el proceso.

En verdad, las imágenes no reproducen de forma objetiva la realidad, sino para ilustrar un cierto contexto histórico, convirtiéndose en fuentes de innegable importancia para la comprensión del comportamiento de las comunidades y de las ideologías de una sociedad en un momento dado. Muchas de las modas y las ondas alcanzaron el lenguaje del cine, infundiéndose la aparición de directores personalistas, que produjeron su propio estilo, y, deseosos de transformaciones sociales, se resultó el surgimiento de sus marcas. Algunos han roto con las lenguas de la narrativa tradicional, siendo incluso incomprendidos. Hoy en día, el cine es un instrumento pedagógico y científico, utilizado en laboratorios y universidades, y nadie puede negar su importancia en los campos del arte y la cultura.

Un plan no es nunca neutral, siendo definido por un número de elementos seleccionados por el autor, es decir, el marco, el campo, el ángulo de la cámara o su movilidad, la duración de la filmación y otros. Estas opciones estéticas, a las que se añaden las múltiples posibilidades que ofrece el montaje, la yuxtaposición de planes, crean un vasto conjunto de convenciones expresivas, con las que el autor se define a sí mismo en relación con el asunto que aborda, expresando de este modo su propia concepción estética y moral. Incluso cuando una película adapta novelas o piezas célebres, incluso intentando mantener la fidelidad al argumento original, se revela el grado de interpretación y opciones estéticas del director, y esto es cierto para las películas de ciencia-ficción y documentales. Tenemos, por lo tanto, como ya fue apuntado, que el cine es un arte profundamente estética y antinaturalista, aunque hay una corriente de cineastas que quieren lograr foros de la neutralidad, dejando al espectador la capacidad de juicio acerca de las realidades expuestas. Aun así, hay diferencias entre el cine de autor, donde predomina la creatividad de grandes directores, y el cine-naturalista de la narrativa tradicional. 
Por fin, devemos recordar que nuestro objetivo en este atículo era apuntar bevemente la importancia de la relación entre cine y educación, y traer informaciones sobre el cine documental. Como parte de una investigación mucho más grande, en la cual pudimos constatar que cuando los estudiantes hacen cine documental, analisando cuestiones sociales polémicas, ellos mismos cambian sus opiniones y se hacen más críticos y humanizados delante de la realidad del mundo, considerando la importancia de estimular a los alumnos a que tengan una formación realmente transformadora, y, además, pensando en las posibilidades que el documental trae, entendemos que este objetivo se dió por cumplido, y esperamos haver contribuído en el análisis del cinema en el contexto educativo, especialente porque se queda claro, en nuestra comprensión, que el documental impulsiona el cuestionamento y la problematización de las realidade sociales, siendo, por lo tanto, de gran ayuda como herramienta didáctica para una educación inovadora.

\section{Referencias}

AUMONT, J.; MARIE, M. Dicionário Teórico e Crítico de Cinema. Campinas, São Paulo: Papirus, 2003.

BRESCHAND, J. El documental. La otra cara del cine. Barcelona: Paidós, 2004.

CARRIÈRE, J. C. A Linguagem Secreta do Cinema. Rio de Janeiro: Nova Fronteira, 2006.

FREIRE, P. Pedagogia da Autonomia: saberes necessários à prática educativa. Rio de Janeiro, Paz e Terra, 1996.

FREIRE, P. Educação como prática da liberdade. 29ª ed. Rio de Janeiro (RJ): Paz e Terra, 2000.

FREIRE, P. Pedagogia do Oprimido. (42a ed.). Rio de Janeiro, Paz e Terra, 2005.

HABERMAS, J. Reason and the rationalization of society. v. 1. Boston: Beacon Press, 1984.

LACAN, J. O estado do espelho como formador das funções do Eu. Rio de Janeiro: Jorge Zaha, 1998.

MELO, C. T. V. O Documentário como Gênero Audiovisual. In XXV Congresso Anual em Ciência da Comunicação, Salvador/BA, Brasil. set. 2002.

NICHOLLS, B. Introdução ao documentário. Campinas, SP: Papirus, 2005.

PARANAGUÁ, P. A. Cine documental en América Latina. Madrid: Cátedra, 2003.

PENAFRIA, M. O Ponto de Vista no filme documentário. In Ciências da Comunicação. Universidade da Beira Interior. La escuela documental: la dimensión visual de lo real Alexandre Buccini, 2001.

PERUZZO, C. M. K. Comunicação nos movimentos populares: a participação na construção da cidadania. (2. ed.). Petrópolis, RJ: Vozes, 1998.

SNYDERS, G. A alegria na escola. São Paulo: Manilie, 2001.

SODRÉ, M. As estratégias sensiveis: Afeto, Mídia e Política. Rio de Janeiro: Vozes, 1992. 